\title{
A sensemaking lens on reliability ${ }^{\dagger}$
}

\author{
RUTH BLATT ${ }^{1}$, MARLYS K. CHRISTIANSON ${ }^{1}$, \\ KATHLEEN M. SUTCLIFFE ${ }^{1 *}$ AND MARILYNN M. ROSENTHAL ${ }^{2}$ \\ ${ }^{1}$ Department of Management \& Organizations, Stephen M. Ross School of Business, University of \\ Michigan, Ann Arbor, Michigan, U.S.A. \\ ${ }^{2}$ Department of Internal Medicine, University of Michigan Medical School, Ann Arbor, Michigan, U.S.A.
}

\begin{abstract}
Summary This study assessed the applicability of current theories of reliability in dynamic settings by exploring the sensemaking processes experienced by a sample of medical residents around lapses in reliability of patient care. Important differences in lapses surfaced, particularly with respect to whether actors were aware that a lapse was occurring in real-time and whether there was anything they could do or say to mitigate or prevent the lapse. In over half of the incidents recounted, the actors did not become aware of the lapse in reliability until after the consequence of the lapse had occurred or the consequence occurred simultaneously with the recognition of the lapse. In other incidents, they faced a critical moment in which they had to decide whether and how to act to intervene in real-time. In the majority of these critical moments, residents had an issue of concern to voice that could have helped mitigate or correct the lapse but instead they remained silent. Issues related to identity and relationships appeared to either inhibit or promote voice during critical moments. We end with ideas for how our findings can inform existing work on reliability in healthcare and the growing literature on voice and silence in organizations. Copyright (C) 2006 John Wiley \& Sons, Ltd.
\end{abstract}

\section{Introduction}

How organizations achieve reliable outcomes repeatedly-how they avoid unwanted and unanticipated variance in performance-is an important but unevenly answered question in organization theory. Organizational scholars have noted two competing approaches to achieving reliability (see Wildavsky, 1991). The first approach focuses on prevention. Advocates of the prevention approach argue that attaining reliability repeatedly requires organizations to anticipate and identify the events and occurrences that must not happen, identify all possible causal precursor events or conditions that may lead to them, and then create a set of procedures for avoiding them (Reason, 1997; Schulman, 2004; Wildavsky, 1991). The second approach focuses on resilience or the ability to maintain positive adjustment under challenging conditions (Sutcliffe \& Vogus, 2003). Scholars in this tradition argue that reliability entails finding ways to cope with, circumscribe, or contain untoward

\footnotetext{
* Correspondence to: Kathleen M. Sutcliffe, Ross School of Business, 701 Tappan Street, Ann Arbor, MI 48109-1234, U.S.A.

E-mail: ksutclif@umich.edu

${ }^{\dagger}$ The first three authors contributed equally and listed alphabetically.
} 
events - such as mistakes or errors - as they occur and before their effects escalate and ramify, rather than trying to preclude them (Weick \& Roberts, 1993; Weick, Sutcliffe, \& Obstfeld, 1999; Wildavsky, 1991).

Both approaches to reliability are grounded in assumptions that rarely are examined, but may not hold in some organizational contexts. The prevention approach assumes that lapses in reliability can be predicted; hence planning and effective system design can prevent them. The resilience approach assumes that lapses in reliability are recognized as they occur; hence coping in real-time can mitigate them. This study was undertaken to shed light on the validity of these approaches by adopting a sensemaking lens and examining how front-line workers (medical residents) in the healthcare context make sense of lapses in reliability, which we define simply as something gone wrong in the care of a patient regardless of outcome (Sutcliffe, Lewton, \& Rosenthal, 2004). Our findings contribute to a more nuanced understanding of reliability in dynamic and complex organizational settings. They suggest that lapses in reliability cannot always be predicted because of the unfolding and shifting nature of organizational events. Yet lapses in reliability cannot always be dealt with in real-time either, because they may not be apparent to actors in the situation or because psychological and social factors may hinder actors' abilities to cope with them.

\section{Sensemaking as lens of inquiry into reliability}

Sensemaking occurs when individuals turn a flow of organizational experiences into words and salient categories that they can comprehend and then use these as a springboard for action (Taylor \& Van Every, 2000; Weick, Sutcliffe, \& Obstfeld, 2005). Sensemaking is triggered by discrepancy, change, or fluctuations in an ongoing flow of events and entails how actors answer two questions: What is the story? and Now what? (Weick et al., 2005). Thus, the sensemaking process encompasses both thinking and action. When people make sense, they act as if something is the case and then test their hunch to discover whether they are right. Sensemaking is as much a matter of thinking that is acted out conversationally in the world as it is a matter of knowledge and technique applied to the world' (Weick et al., 2005: 412). Furthermore, issues of identity are often involved in sensemaking; when people face events that disrupt normal expectations, they use their identity and personal experience to make sense of ambiguous stimuli and compose a sufficiently plausible story of what is happening so that they (and others) can take action (Brown, 2000). Finally, sensemaking is social; it is in and through interactions with others that organizational members interpret their environment and construct accounts that allow them to comprehend the world (Maitlis, 2005). This means that it is also a process of power, influence, and persuasion (Weick et al., 2005).

We use sensemaking as both a method and an object of inquiry (for a similar distinction on the use of narrative in research, see Ewich and Silbey (1995)). Sensemaking, as a method of inquiry, acts as a lens that focuses our attention on human agency, equivocality, and relationships. It focuses our attention on agency because action is viewed as part of people's efforts to make sense; on equivocality because sensemaking is triggered by people's need to understand an equivocal flow of experience; and on relationships as sensemaking is social (Weick et al., 2005). Sensemaking as an object of inquiry means that a study results in findings about the sensemaking processes that organizational actors undergo.

We use sensemaking as a method of inquiry to evaluate the two approaches to reliability (for a review of the two approaches see Schulman (2004)). Both the prevention and resilience approaches make assumptions about how actors comprehend the flow of organizational experiences and how they turn this comprehension into action. The prevention approach assumes that a lapse can be identified a priori. Moreover, action during the occurrence of a lapse develops out of anticipation. That is, during the actual lapse, actors are assumed to turn to procedures that specify in advance how they are to act under 
such circumstances as guidelines for action. However, critics of the prevention approach argue that it is based on a static view of organizations and that working conditions often fluctuate in ways that cannot be known in advance, presenting individuals with problems of high variety and significant novelty (Weick et al., 1999). In order to perform reliably, variable work contexts must be capable of assuming more conditions or system states than can be anticipated or planned for in formal designs. Thus, critics claim, the prevention approach cannot be expected to work in changing contexts. The resilience approach aims to overcome this limitation by focusing on individuals' activities as they manage and cope with fluctuations in reliability in the moment. Yet the resilience approach assumes that the occurrence of a lapse can be recognized in real-time. Once a lapse is recognized, actors enact their experiential and tacit knowledge by improvising to mitigate the lapse (Schulman, 2004). By gaining insight into the interplay of action and interpretation during lapses in reliability by front-line workers, a sensemaking lens enables the evaluation of these assumptions, and therefore, the appropriateness of the two approaches to reliability in the healthcare context.

We also used sensemaking as an object of inquiry to shed light on the sensemaking processes that actors undergo during lapses in reliability. Specifically, we wanted to explore how residents make sense of lapses in the day-to-day care of patients and how they manage and cope with these lapses. Studies of sensemaking typically have leveraged dramatic incidents such as the Tenerife air disaster (Weick, 1990) or the shooting down of two Blackhawk helicopters in a friendly fire incident (Snook, 2000). However, sensemaking also occurs in response to pervasive punctuations in everyday organizing. In fact, contexts more closely associated with the everyday experiences of managers and people on the front lines are common, but relatively understudied, occasions for sensemaking (for an exception, see Patriotta (2003)).

\section{Reliability and healthcare}

Healthcare is an excellent setting for examining the applicability of the two approaches to reliability and how actors make sense of lapses in context because the process of providing patient care is highly variable with multiple discontinuities and because reliable performance is so important. As noted earlier, a core issue in studies of reliability has been the role of variability and unpredictability. Consequently, healthcare serves as an appropriate context for assessing the extent to which a prevention approach can indeed work when working conditions fluctuate as well as whether real-time recognition of lapses is possible.

Although some aspects of healthcare are predictable and lend themselves to routinization, overall, caring for patients is inherently variable and unpredictable. This variability and unpredictability in healthcare comes from a variety of sources: the wide range of clinical conditions that patients might present with; the difficulties inherent in diagnosis, particularly as patients' medical conditions evolve and change over time (Paget, 1988); the frequent transitions or handoffs between healthcare providers, either as the patient moves between various parts of the healthcare system or as care providers change, which place patients at high risk for mishaps (Patterson, Cook, Woods, \& Render, 2006; Solet, Norvell, Rutan, \& Frankel, 2005; Vidyarthi, 2004), and the frequently changing team compositions (Edmondson, 2003), resulting in teams in which individuals may have very little experience working together. Moreover, in inpatient hospital settings, care is provided by multiple professionals who differ in social status and power, professional languages, and ways of communicating, which increases complexity and adds to the challenges of effective coordination. Additionally, many positions in healthcare organizations are staffed by temporary workers, which means that much care is delivered by transient, temporary groups that are assembled at the bedside (Kohn, Corrigan, \& Donaldson, 2000). 
Healthcare is also an appropriate context for our research goals because reliability is so important. Few would disagree with the need to better understand the dynamics of managing and recovering from untoward events in the care of patients. Lapses in reliability in the form of errors, mistakes, and mishaps (terms that we use interchangeably) can be lethal to patients if they are not corrected in a timely manner. And although the societal harm related to lapses in care is less obvious than harm resulting from a catastrophic event, such as a chemical spill or nuclear plant malfunction, when individual medical errors are considered in the aggregate, the large cumulative burden of harm becomes obvious. The Institute of Medicine (IOM) estimates that medical errors in United States inpatient settings result in high levels of preventable deaths (44 000-98 000 per year) and that up to 3.7 per cent of all hospitalized patients experience an injury resulting from medical intervention (Kohn et al., 2000); other errors with less serious consequences are also pervasive. ${ }^{1}$ In addition, the potential for organizational harm in terms of reputation and legitimacy, as well as for real resource losses (e.g., liability claims or lost markets), is fueled by the current legal and regulatory environment in the United States. For example, Johns Hopkins University Medical Center temporarily lost all federal research funding in 2001 after the death of a healthy volunteer in an asthma study.

Given the magnitude of adverse consequences of unreliable performance in healthcare, it is not surprising to find that studies of error have been prominent in medicine and medical sociology for decade (Kohn et al., 2000; Rosenthal \& Sutcliffe, 2002). Still, gaps remain. First, the existing literature has focused mostly on defining medical error (e.g., Hayward \& Hofer, 2001) and estimating its incidence (e.g., Thomas, Lipsitz, Studdert, \& Brennan, 2002). Few studies have focused on understanding the mechanisms and processes that underpin lapses in reliability and safety (Hoff, Jameson, Hannan, Flink, \& Osten, 2004) or enable clinicians and organizations to manage, cope with, and recover from errors and mistakes once they become manifest so that they can be corrected before causing harm to patients (see Carthey, de Leval, and Reason (2001) for an exception). Understanding mechanisms is a prerequisite for improving reliability in healthcare. Also, few studies have tried to understand the experience of error from the perspective of those who provide care (cf. Volpp \& Grande, 2003).

Our study aims to fill these gaps in our understanding of reliability in healthcare, as well as provide insight into the broader question of how organizations can achieve reliable outcomes amidst complexity and dynamism. We used qualitative methods to explore how medical residents, who are front-line practitioners in a complex and dynamic organization (a large teaching hospital), experience medical mishaps, which are lapses in reliability. Qualitative research is particularly appropriate for investigating complex processes as they unfold over time (Lin, 1998: 167), which is the case with medical work. Moreover, it is well-suited to using a sensemaking lens, since it entails understanding the context of action from the perspective of the participants (Weick, 1995). Our findings allow us to evaluate current approaches to reliability and to better understand the sensemaking processes that accompany lapses in reliability as they occur.

\footnotetext{
${ }^{1}$ While there is controversy over the accuracy of the IOM estimates (see Hayward and Hofer (2001) and Thomas et al. (2002)), it is clear that preventable medical errors are resulting in loss of life.
} 


\section{Organizational Context}

Hospital: University Hospital (fictitious name) is a 550-bed inpatient academic medical center located in the mid-Western United States, which ranked among U.S. News and World Report's 'Best Hospitals' in 2004. In the University Hospital health system, there are over 90000 emergency services visits per year and approximately 31000 admissions per year.

Healthcare Climate: It is important to note that the data for this study were collected during a time when the awareness of medical error for both medical personnel and the general public was at an unprecedented all-time high. The publication of the Institute of Medicine's (IOM) report (Kohn et al., 2000) To Err is Human received significant media coverage; the report claimed that 44000 98000 deaths due to preventable medical error occurred every year in U.S. inpatient facilities. In addition to coverage in the popular press, the issue of medical error was receiving a significant amount of attention in the medical literature where there was an ongoing debate about the accuracy of the figures quoted in the IOM report, how to classify medical error, and how to begin to attempt to decrease the harm to patients from medical error.

Time: The data for this study were collected from 1999 to 2002.

\section{Methods}

\section{Sample and procedure}

We conducted our study in a 550-bed U.S. teaching hospital with a large graduate medical education program. We chose to study residents, a relatively understudied group, because they are the front-line medical staff involved in the day-to-day care of patients. Consequently they are in situations where they make sense of complex evolving organizational events. Residents provide the in-house after-hours coverage of patients and are often the first physicians to be involved in admissions and crises. As such, they are likely to be present in the moments leading up to and immediately following lapses in reliability.

To assure a representative sample of respondents, we selected a random sample of 26 residents from the total population of 85 residents and stratified the sample by year of residency, gender, and specialty (Surgery, Medicine, and Obstetrics/Gynecology (OB/GYN), the three specialty residency programs sponsored by the hospital). The final sample consisted of 14 men and 12 women: 5 from surgery, 17 from medicine (11 medicine and 6 preliminary/transitional), and 4 from OB/GYN. Residents ranged in age from 25 to 39 years and averaged 29.8 years. Eleven residents were in their first year of postgraduate training, five in their second year, seven in their third year, two in their fourth year, and one in their fifth year. Because students go on to residencies in other programs after completing the first year, there was a disproportionate number of first-year residents in the sample and population.

\section{Data collection}

We contacted respondents first by letter and then by telephone. Because of the highly sensitive nature of the study, we conducted the interviews in a private office in the institution's educational center, which was located away from the inpatient setting or in the interviewer's office. 
We used a semi-structured interview format to collect the data. After gathering basic demographic information from each respondent, we wanted to get a sense of how the residents thought about lapses in reliability. We asked each respondent to tell us what the term 'medical mishap' meant to them. ${ }^{2}$ We used the term 'medical mishap' because we wanted to avoid the negative, judgmental connotations of 'mistake,' or 'error' and the formal implications of 'adverse event' and because we wanted residents to think broadly about lapses in reliability in patient care. We then asked a series of questions about the residents' typical work environments, including daily activities and patterns of communication. Questions included 'Who do you talk to? What are the patterns of communication? With whom and how often do you communicate? With whom do you have the most contact? If you thought something were going wrong, who would you talk to first?' These questions gave us a window into the typical relational and communication patterns that characterize respondents' daily work lives.

Next, we asked each respondent to think about two or three medical mishaps in which he or she had recently been involved (lapses they had witnessed as well as caused) and then to describe each mishap in depth. Follow-up questions for each mishap included questions about the situation on the unit during the mishap, the condition of the patient, who was involved, what was the outcome, contributing factors, how the mishap was acknowledged, and how it could have been prevented. The interviews lasted between 1 and 2 hours, were recorded, transcribed, and assigned a unique identifier.

\section{Analyses}

Analysis followed the grounded theory approach of traveling back and forth between the data and our emerging theory (Glaser \& Strauss, 1967; Locke, 2001). That is, we assigned meanings (codes) to units of data, analyzed the codes for themes and emerging theoretical insights, and then returned to the data for further coding and analysis in light of these emerging theoretical insights. Our criterion for what constituted a theme was its salience as an explanatory factor rather than its frequency (Glaser \& Strauss, 1967), reflecting our goal of uncovering mechanisms (what is occurring and how is it occurring) rather than establishing frequencies (how much of it is occurring) (Lee, Mitchell, \& Sablynski, 1999; Yin, 1994).

The analysis proceeded in the following stages. First, we read all of the transcripts and generated a broad list of codes representing initial themes in the data. This initial list included codes related to the residents' everyday routines as well as unexpected events that occurred during the course of their work, interactions with colleagues, supervisors, other professionals, and patients, and organizational and professional norms related to preventing and managing mishaps. At this stage, we began to develop a sense of what residents' work was typically like-both in terms of the content of their work and the context in which that work was performed. At the end of this stage, we generated a single coding scheme of factors that played a role in the mishaps with a hierarchical structure that divided the codes to individual-level (e.g., inexperience), dyad-level (e.g., poor relationship), and collective-level (e.g., deference to superiors) factors (as per the guidelines of Miles \& Huberman, 1994). We then coded all transcripts with this new coding scheme.

In the second stage of our analysis, we began to focus on residents' descriptions of how they made sense of each lapse in reliability. We coded these descriptions by asking ourselves as we read, 'What are the important concepts, processes, and tensions related to how they detect and manage mishaps?' We also coded the incidents based on whether the resident was aware that a lapse in reliability had occurred as it was unfolding, whether there was any time between when the lapse in reliability occurred and when the consequence of the lapse occurred, and whether the resident chose to take any action to mitigate or correct the lapse. At this stage we identified that there were some moments in time that

\footnotetext{
${ }^{2}$ Currently, there is no consensus within the medical literature about the terminology related to medical error and a vast number of terms are used, including error, mistake, accident, incident, lapse, adverse event, untoward event, negligent adverse event, near miss, and potential adverse event, to name a few (Rosenthal \& Sutcliffe, 2002).
} 
seemed especially critical in coping with lapses in reliability (which we call 'critical moments'). As we iterated between data and analysis, we found that these moments were windows of opportunity for actors to mitigate or correct lapses in reliability through speaking up about an issue of concern.

For our final stage of analysis, we coded how the residents behaved during these critical momentsdid they speak up or did they remain silent? We developed a new coding scheme that reflected our emerging focus on factors influencing the propensity to voice concerns versus keeping silent during critical moments. The codes in this new scheme included both codes that were generated from the data in the previous analyses (inductive codes, for the purpose of theory generation), as well as new codes derived from our reading of the literature on voice and silence (deductive codes, for the purpose of theory elaboration) (Lee et al., 1999; Miles \& Huberman, 1994). The latter included, for example, codes for different kinds of risks (career, image, relational) (Dutton \& Ashford, 1993; Milliken, Morrison, \& Hewlin, 2003) and motives (prosocial, defensive, acquiescent) (Van Dyne, Ang, \& Botero, 2003) associated with voice and silence.

In all three stages of the analysis, we read and analyzed the passages that were coded in each of the codes for theoretical insights across cases. We also conducted within-case analysis, discussing how the constructs in our emerging theory interrelated in each case. At the final stages of theory development, we created tables in which we explored the theoretical properties of our constructs and assessed the extent to which we had empirical support for these properties. We also discussed how our themes related to one another and to existing organizational theories (Glaser \& Strauss, 1967; Locke, 2001).

\section{Findings}

Respondents reported a total of 77 mishap incidents that they had witnessed or had been personally responsible for, which ranged in severity from situations where a lapse in reliability occurred but did not result in harm to the patient (e.g., an incident in which two patients' orders were switched, and a nurse noticed the switch and corrected the orders) to situations where the lapse in reliability contributed to the death of a patient (e.g., an incident where a delay in diagnosis resulted in a patient not receiving the appropriate treatment for his condition). Most of the incidents described involved an intermediate level of harm to the patient, such as a lengthened stay in the hospital or a specific treatment required to remedy the consequence of the lapse (e.g., administering an antidote for a medication that was given in error). It is important to note that the mishaps reported by the residents were active errors, defined as errors whose effects are felt almost immediately (Reason, 1990), rather than latent errors, defined as uncorrected deviations from procedures and policies that do not have direct adverse consequences (Ramanujam \& Goodman, 2003). Thus all of the mishaps were in fact lapses in reliability rather than potential lapses in reliability.

Below we present our findings regarding how the lapses in reliability differed with respect to whether actors were aware that a lapse was occurring in real-time and whether there was anything they could do or say to mitigate or prevent the lapse. Next we consider our findings in light of our research questions: (1) What do we learn about the two existing approaches to reliability in this setting (prevention vs. resilience)? and (2) What do we learn about the sensemaking processes of residents as they encounter lapses in reliability?

\section{Types of lapses in reliability}

We found that the incidents could be classified into three categories based on: (1) whether the actors realized a lapse in reliability was occurring in real-time, (2) whether there was an opportunity for the 
Table 1. Categories of incidents according to awareness of lapse and ability to mitigate or correct it

\begin{tabular}{lccc}
\hline Category of incidents & $\begin{array}{c}\text { Number of } \\
\text { incidents }\end{array}$ & $\begin{array}{c}\text { Per cent within } \\
\text { category }(\%)\end{array}$ & $\begin{array}{c}\text { Per cent of total } \\
(\%)(n=77)\end{array}$ \\
\hline $\begin{array}{l}\text { Category 1: Actors did not realize that } \\
\text { a lapse in reliability was occurring }\end{array}$ & 14 & & 18.2 \\
$\begin{array}{l}\text { Category 2: Actors did realize a lapse was } \\
\text { occurring but there was nothing they could do }\end{array}$ & 35 & & 45.4 \\
$\begin{array}{l}\text { Subcategories } \\
\text { 2.1 Coincident lapses and consequences }\end{array}$ & 16 & 45.7 & 20.8 \\
$\quad$ 2.2 Inherited lapses & 15 & 42.9 & 19.5 \\
$\quad$ 2.3 Limits of medicine & 4 & 11.4 & 36.4 \\
$\begin{array}{l}\text { Category 3: Actors did realize a lapse was } \\
\text { occurring and there was something they could do }\end{array}$ & 28 & & 14.3 \\
Subcategories & & & \\
$\quad 3.1$ Actors corrected or mitigated the mishap & 11 & 39.3 & 22.1 \\
$\quad$ by exercising voice & 17 & 60.7 & \\
$\quad$ Actors remained silent and did not correct & & & \\
$\quad$ or mitigate the mishap & & & \\
\hline
\end{tabular}

actors to do something to mitigate or correct the lapse, and (3) whether they took action. These categories and their subcategories are displayed in Table 1.

First, we find that a significant percentage of the incidents (18.2 per cent) involved lapses in reliability that were only apparent in retrospect. The following quote, describing an incident in which an elderly man was admitted with a fever of unknown origin, illustrates a situation where the lapse in reliability is only apparent after the fact:

He came to the ER with a fever of unknown origin and fatigue ... And they did a chest X-ray work up, urine, blood test, $C B C$, chem 7, it was negative [i.e., no source of infection could be found]. They couldn't figure it out. So, he wasn't given antibiotics because they didn't know the source of the fever... When they rounded on the patient in the morning, they repeated the chest X-ray. And it turned out that there was a pneumonia and they gave him antibiotics. But it was too late. So he became septic quickly and he died. So, I don't know if he was given the antibiotic earlier during the night, 12 hours earlier, maybe that could have saved his life.

This quote highlights that physicians can undertake actions that may seem appropriate in the moment but that turn out to be mistaken in retrospect. The actors in this incident followed standard care for patients with fever of unknown origin who are stable (as this patient was), which is to identify the source of the infection before administering antibiotics. However, as the situation unfolded and the true diagnosis of pneumonia became apparent, they realized that their course of action was inappropriate. Our finding that actors often are only able to appreciate that a lapse in reliability has occurred by working backward from the adverse outcome is consistent with Paget's (1990: 142) observation that errors are not always apparent in real-time: 'The journey of error, the dynamic experience of going wrong, is crucial in understanding medical mistakes. They are rarely simple events like errors in addition. Rather they are complex activities and cognitions that unfold in time.' Medical work is uncertain and entails significant ambiguity and dynamism. Actors sometimes work with incorrect diagnoses, continually changing circumstances, and at times lack the skills or knowledge to handle emerging problems appropriately. These aspects of medical work can prevent practitioners from becoming aware of a lapse in reliability until its consequence has already occurred.

The second category consists of 35 incidents (45.4 per cent), in which actors realized a lapse was occurring but there was nothing they could do to prevent the adverse consequence of that lapse. Our 
analysis revealed that these incidents differentiated themselves into three subcategories based on the reasons why actors were unable to prevent the adverse consequence despite being aware of the lapse: situations where the lapse and the consequence were coincident, situations where the lapse was inherited from other providers, and situations where the limits of medicine were reached.

In 16 of these instances (45.7 per cent of this category), the lapse and its consequence were coincident. Put simply, there was no time to prevent the consequence of the lapse because the lapse and its consequence occurred simultaneously. Without exception, these lapses occurred during the execution of a procedure. Two examples include a resident who accidentally punctured a patient's lung while placing intravenous (IV) access (central line) in the large veins of the patient's neck and a nurse who accidentally let go of a nasogastric tube when she moved a patient from one position to another, which resulted in the tube slipping into the patient's stomach (requiring removal by a surgeon).

In 15 instances (42.9 per cent), the lapse in reliability had already occurred before the resident received the patient for care. Although the residents could attempt to mitigate the consequences of the lapse, they could not prevent the consequence from occurring. An example of this type of lapse is an incident where an Internal Medicine resident admitted a patient who was being transferred from another hospital and realized that the patient had been misdiagnosed and required radically different treatment from the type she had been receiving.

Lastly, in four instances (11.4 per cent) residents characterized mishaps that seemed to represent situations in which the limits of medicine were reached. That is, something went wrong in the care of the patient, but it was not clear why, and even though everything possible had been done to help each patient, an adverse outcome occurred. This situation is illustrated in one resident's description of a patient who died despite extraordinary efforts on the part of involved caregivers:

I was in the CCU [Critical Care Unit]. I was up all night with this patient. No one knew what had happened. She injured her spine one day and the next day she just crashed. No one really knew, and I happened to be there all night with the family, with the patient. You know I think we went the extra mile with her-to be there and doing things that we wouldn't do with regular patients. And she died the next day.

Finally, in the third category, 28 incidents (36.4 per cent of total incidents) represents lapses in which the actors were aware that a lapse in reliability was occurring and there was an opportunity to intervene to prevent the lapse from reaching its consequence. These incidents represent critical moments in patient care where something potentially can be done in real-time to prevent the adverse consequence of the lapse from reaching the patient. In these critical moments, actors must decide whether or not to intervene. In 11 of these 28 incidents ( 39.3 per cent), actors chose to intervene to correct or mitigate the lapse by voicing their concern. In 17 of them (60.7 per cent), actors chose not to intervene and remained silent.

Residents intervened in 11 cases and this intervention corrected or mitigated the mishap. For example, an 87-year-old man with Hepatitis $\mathrm{C}$ had been complaining of abdominal pain. Whereas the attending (the supervising physician) attributed the pain to the Hepatitis $\mathrm{C}$ and did not think that further diagnosis was necessary, the resident attempted to intervene by voicing her opinion that the patient should receive further evaluation from a gastroenterologist. The resident tells,

We had a gastroenterologist come and advise on the case. That was controversial ... the attending didn't like the idea and thought it wasn't necessary. When the gastroenterologist came, he thought it was ridiculous that the liver failure was being attributed to the patient's illness and that there must be something other than that that was wrong. When he did the upper endoscopy [a procedure where a patient swallows a small camera to look at the esophagus and the stomach] he found that what was bleeding was not esophageal varices [esophagus blood vessels] but gastric varices [stomach blood 
vessels]. When the gastric blood vessels are engorged and bleeding generally it means that the vein going to the spleen is thrombosed [clotted shut].

Splenic vein thrombosis is an entirely different cause of liver failure than Hepatitis $\mathrm{C}$ and requires substantially different treatment. As the quote indicates, the resident's voice enabled correction of this misdiagnosis and paved the way for appropriate treatment.

The remaining 17 incidents involved critical moments during which residents realized a lapse was occurring but chose not to intervene. As we present below, this choice involved remaining silent about an issue of concern. In describing these incidents, residents expressed the belief that their silence contributed to the adverse consequence subsequently experienced by the patient. Many expressed regret that a medical mishap may have been mitigated if they had only expressed their voice or been more persistent in voicing their concerns. For example, a third-year Internal Medicine resident tells of an incident that involved an elderly patient admitted with a blood clot (thrombosis) in the superficial vein of her leg, a condition that is usually treated with warm compresses, rest, and anti-inflammatory drugs. The resident disagreed with the attending physician's treatment plan of thinning the blood, a more aggressive treatment that carries the risk of causing internal bleeding and that is usually reserved for blood clots in the deep veins of the leg. The resident was concerned that the treatment was both inappropriate and unnecessary:

We don't thin the blood of patients who have superficial vein thrombosis. Like, I've never heard of it. But the attending admitted her for that purpose. And we all sort of looked at it in the beginning and said 'Why are we doing this?' And threw our hands up in disgust and said 'You know what, we're not going to be that kind of an attending when we're an attending.'

However, the resident did not voice her concern and, unfortunately, the patient developed massive internal bleeding as a result of the treatment with the blood thinner and almost died.

This finding that residents remain silent during critical moments (in 60.7 per cent of the incidents where residents were both aware of the lapse in real-time and had an opportunity to intervene) contrasts with a broader finding evident across all of the cases that the work life of residents entails continuous voice as an ongoing part of patient care. We found that in their everyday work residents continually speak up, seek information, inquire, and express their concerns in order to figure out what is happening with the patient and what to do about it. They do this, for example, by proactively voicing a question or series of questions that reveal their confusion about the state of a patient. The following quote from a first-year Internal Medicine resident describing how he used voice to figure out what was wrong with the patient is illustrative:

I had a patient come in and the whole situation was just a bad situation, because [the patient] was a direct admit from the private physician. And so he came to the floor with no information, no labs, and when I went to talk to him I said, 'So why are you here?' And he said, 'Well, my doctor checked my blood work and my numbers were up.' And that was the history that I had. And then I called the attending on call who was covering for the attending who admitted the patient. And she didn't know a whole lot either. Eventually I got out of someone that he was in for acute renal failure.

Residents cope with incomplete information and yet face significant time pressures. Compounding this, they often are unfamiliar with the other providers involved in the case. In order to do their work, they must repeatedly proactively speak to others in order to gather information. This voice is made easier by virtue of their position as learners. Beyond information gathering, residents voice their opinions about the proper course of care. Residents also voice when they think something is wrong, when they notice a discrepancy, a change, or a surprise. In the following example, a first-year resident expresses voice to an attending physician that the patient requires more care than she can give, 
It was a patient who had had surgery and had some type of underlying coagulation problem and he was hemorrhaging from his leg... Essentially what I did with this patient all night long was give him as much blood products as I could possibly give him as fast as I could possibly give it ... And I did contact the surgeon who had done the surgery and asked him if he would please, I called him at home, and asked him if he would please come back to the hospital three times and he wasn't very happy about it but he did come back twice from home and do what he could to control the bleeding.

As this quote shows, when something is wrong, voice and action go together. Residents act in order to do their best when they think something is wrong, and they also voice their opinion that something is wrong to others in an attempt to mobilize more resources for care. Front-line patient care comes with the responsibility to act on behalf of patients, which necessitates speaking up about issues of concern and acting to resolve them. This observation is consistent with our finding that residents regularly voice their opinions about patient care in their everyday work. In light of this modus operandi, our finding that residents often remain silent during critical moments is striking.

\section{Evaluating limits of current approaches}

Our first research goal was to evaluate the validity of current approaches to reliability in this context. Overall, our findings challenge aspects of both prevention and resilience perspectives as they pertain to inpatient hospital settings. Reliability through prevention requires identifying lapses that must not occur, understanding the causes of those lapses, and setting up clear routines and procedures to either prevent the lapse in the first place or prevent the lapse from resulting in an adverse consequence. But respondents' accounts revealed that the lapses experienced were highly variable, novel, and often unexpected, making planning ahead difficult. Additionally, residents' rich descriptions of their day-today routines revealed that their work was physically and temporally distributed, which rendered the following of routines and procedures that guard against and preclude events particularly difficult (Schulman, 2004). This is not to say that we found no events that could have been prevented. Clear deviations from standard procedures resulted in lapses in several incidents. In one, a 'Do Not Resuscitate' order was not followed and the patient was inappropriately resuscitated. In another, a patient developed a medication-resistant wound infection after a clinician used a non-sterile technique while reinserting a venous access device. Yet our findings reveal that much of the work of patient care includes coping with the non-routine and unpredictable, even when one expects the routine.

As an example of an ostensibly routine situation that was actually non-routine, a woman with a history of two uncomplicated pregnancies and deliveries arrived to the obstetrics ward in labor. She had not received much prenatal care in this pregnancy but was otherwise healthy. Assuming a normal, healthy, and single-baby pregnancy, the staff considered her low priority for an ultrasound at the bedside. However, during delivery, it became apparent that she was actually pregnant with twins. Moreover, one of the twins had died in utero, probably several days before she went into labor. With this discovery, the routine instantly became the non-routine.

Our findings suggest that there are limits to the resilience approach to reliability as well. To circumscribe, cope with, or contain lapses before they result in harm requires that lapses be made visible to actors and that they can take action to remedy the situation before harm occurs. Respondents' accounts revealed that these features are often missing; in fact, we found that 63.6 per cent of the incidents did not meet these basic criteria. Actors often do not know that a lapse has happened until after it has occurred, as was the case in the first category of incidents (18.2 per cent). At other times actors face situations in which they know a lapse has occurred but cannot do anything about it, as was the case in the second category of incidents ( 45.4 per cent). In such incidents, there is a limited role for 
the improvisational actions, tacit knowledge, and experience-based real-time coping that the resilience approach calls for (Schulman, 2004). Moreover, as we present in the next section, even when actors are aware that a lapse is occurring and have the opportunity to intervene, they oftentimes do not. Thus, our findings suggest that while the resilience approach is more appropriate in this setting, there are still limits to its applicability.

\section{Sensemaking about lapses in reliability}

Our second research goal was to gain insight about the sensemaking processes that actors use when lapses of reliability occur. Over a third of the incidents (28 mishaps or 36.4 per cent of total incidents) reflect situations in which actors realize that a lapse is occurring. These incidents are distinguished by what we call 'critical moments' in patient care: points in time when a lapse in reliability has been noticed but the consequence of that lapse has not yet been fully realized. In critical moments, speaking up about a lapse in reliability makes the lapse visible to others, allowing for organizing to mitigate or correct the lapse. Thus the opportunity for resilient reliability, or real-time coping, exists. Our analyses reveal that residents' sensemaking processes are strongly shaped by their identities and by their interpretation of the favorability of the relational environment to voicing or remaining silent about issues of concern raised by the perceived lapse. Sensemaking, in turn, plays an explanatory role in whether the lapse is mitigated, or handled in a reliable manner.

In the majority (17/28 or 60.7 per cent) of the incidents in which the actor realized in real-time that a lapse was occurring and had the opportunity to intervene, they chose to remain silent. One example, in which a resident remained silent about a concern that something was wrong with a patient, involved a young diabetic patient who was admitted to the hospital for IV antibiotics to treat an infected foot ulcer. The resident noticed that the IV antibiotics were at the bedside but had not been started and walked out of the room without noting his concern to the patient's primary nurse. The nurse did not start the antibiotics and there was a significant delay in treatment. This delay was problematic because timely antibiotic treatment is critical in the management of diabetic ulcers; if the ulcers are not treated properly, patients may eventually need to have the affected limb amputated.

These instances of choosing to remain silent despite noticing an issue of concern were anomalous given our finding of continuous voice as part of everyday patient care in this context. As we described earlier, residents act in order to do their best when they have an issue of concern, and they also voice their issue of concern to others in an attempt to mobilize more resources for care. During a critical moment, ongoing voice can serve to correct or mitigate a mishap, as we found in the 11 incidents in which residents did speak up.

Yet we also found that critical moments for voice are fragile. Voicing or remaining silent during critical moments are part of a sensemaking process that is shaped by identity as well as social and relational dynamics. Our findings suggest that residents' evolving identities from novices to experts influence the extent of their confidence in an issue, which in turn affects whether they speak up about a possible lapse in reliability. Residents struggle to find the appropriate balance between being a student who is still learning and a professional who ought to already know what to do. Regardless of seniority, the stronger their identity as physicians, the more confident the residents are in their opinion or observation, and the more likely they are to voice concerns. This sense of confidence is also grounded in knowledge about or experience with the particular issue. Residents who do not feel confident about their assessment of the situation are more likely to remain silent. That is, when residents are particularly aware of being novices, lacking knowledge and experience about a particular problem as compared with others in the situation, then they may self-censor and remain silent. This is revealed by a resident who tells of an incident that occurred when she was an intern (first-year resident), 
If I had more confident knowledge as to the problem on hypernatremia [high levels of sodium in the blood] at the time, I would have questioned what I thought I heard ... I would have said to myself 'Well the ER made a mistake. Even my resident, he doesn't mean that. So, that's not the way to do this.'

Yet even when residents are confident about the issue of concern, they assess whether their enactment of voice will be received favorably or unfavorably based on their understanding of the specific dynamics of the relationship with the recipient of the voice. This finding of the importance of specific relationships contrasts with previous work that emphasizes the role of the broader organizational context for risk taking and speaking up about concerns (Edmondson, 1999). Unless they perceive the relationship to be unfavorable, residents will voice their concern because, as we found, voicing is the default behavior in this context. But relational considerations sometimes steer the choice away from voice and toward silence. We identified two relational considerations: the first was the expectation of negative outcomes for the self or others, and the second was the anticipated effectiveness of voice, which was based on the actor's assessment of how the particular person had responded to voice in the past or how voice would affect the future of the relationship.

The first relational consideration is whether voice will lead to negative outcomes for the self or others. For example, residents sometimes worry that someone else will interpret their voicing the issue of concern as a sign of incompetence. As a third-year Internal Medicine resident said, 'I'm going to be an attending in less than 5 months and I want to-I feel like I'm ready to be the attending and I need to prove that I'm ready to be the attending.' In fact, sometimes voice does result in others' perception that the resident is incompetent, as in the following incident told by a second-year Internal Medicine resident,

When I presented the patient and I said 'The patient's sodium has corrected after the free water but it has corrected too fast.' I was the one who had mentioned that it was too fast because it's back down to normal. [The attending] said 'Well, you could have killed the patient.' That was his response to me.

Another kind of negative outcome that residents fear is punishment. Residents learn which attendings are particularly averse to their input and are more likely to be silent with those attendings than with others. Finally, residents sometimes consider whether the voice will lead to a negative outcome for the recipient of the message and withhold voice out of consideration. In the following example, a second-year Internal Medicine resident silenced her concern that something was wrong, thereby exacerbating the mishap, because she did not want the recipient of the message to suffer a negative consequence,

[The mishap] could have prevented if I would have paged him and said 'Hey, did you really mean normal saline?' But I have to say the reason I didn't do it, and I don't want to just justify things, but these are the kinds of things that sometimes happen because he was very sick at night too. The [senior] resident was sick. And he couldn't stop sneezing. It was so bad he couldn't get a sentence out. He was prescribing medication for himself and was waiting for the pharmacy downstairs to give him medication. When I thought about calling him I thought 'My goodness he's probably getting a little bit of rest.' It was four o'clock in the morning.

These findings are consistent with two of the three motives that Van Dyne et al. (2003) identified to underlie voice and silence: self-protection (or fear) and other-consideration (or cooperation). An important distinction, however, is that the motives stem from the particular history of the relationship, rather than the stable orientation of the actor or as a result of stable features of the setting. 
The second relational consideration is whether voicing to the particular person is likely to be effective. We found that residents remembered how people responded to voice in the past and took this response into consideration in their decision whether to voice. As a third-year OB/GYN resident tells of a particular attending,

The attending is the main factor. I don't want to say 'stubborn' but set in her ways. And wanted to do it her way; wasn't taking much input. This attending is just excellent but sometimes you just can't change her mind. She's intimidating.

In light of her experience with this attending, the resident chose not to speak up when she noticed that the attending prescribed the wrong medicine for a patient.

Sometimes this anticipated ineffectiveness was accompanied by concern for the future of the relationship. For example, in the following quote, the resident did not speak up in part because she was worried about how her action might affect the relationship,

If I felt like I could actually communicate with that group of attendings I would have tried but I didn't feel like it would be useful for me. And all it would have done would be inflamed the relations between me and that attending and the patient still would have ended up getting [the wrong treatment].

The anticipated ineffectiveness consideration for silence is associated with feelings of resignation, which was theorized by Van Dyne et al. (2003) to be the third motive underlying voice and silence. Again, however, our findings suggest that this consideration arises out of the particulars of the relationship rather than characteristics of the actor or the organizational climate.

The decision of whether or not to speak up is not a single choice-point. Because of the need to continuously voice as part of patient care, residents frequently face the question of whether to voice or remain silent. As events unfold and the condition of the patient or the context changes, residents continue to make choices about whether to voice or silence their issue of concern. Thus, in some of the instances, silence initially began with voice, but the attempt at voice was not heard and the action the residents were hoping to prompt did not occur. When voice was initially ineffective, residents sometimes spoke up again more forcefully, spoke up in a different way, spoke up to a different person, or remained silent. Thus speaking up in itself triggers a new process of interpreting how the voice act was received.

Because the voicing process is iterative, residents may learn as an incident unfolds whether the relationship is favorable to voice. In the following example, a second-year Internal Medicine resident exercised voice to try to convince surgeons to operate on a patient with a bowel obstruction. They failed to listen, refused to do the surgery, the resident gave up, and the patient died. Reflecting on the incident, she speculated that the mishap could have been prevented if someone had continued to voice the opinion that surgery was necessary, but that her own attempts at voice with the surgeons were ineffective in bringing about the desired outcome,

Probably this should have been an attending-to-attending conversation rather than me trying to harass them myself. And also the surgery residents are hard to get a hold of, you can't read their signature, they don't call back with the patient, things like that.

Thus our findings suggest that residents' identities and confidence in the issue as well as their assessment of the favorability to voice of their relationships with others constitutes part of their sensemaking during critical moments. Although professional norms and the demands of patient care call for voicing issues of concern, particular features of the residents' identities and relational dynamics with other practitioners can lead them to choose silence. 


\section{Discussion}

Our study had two goals. The first was to assess the appropriateness of the prevention and resilience approaches to reliability in a dynamic context such as healthcare. The second was to better understand residents' sensemaking processes during lapses in reliability. Figure 1 summarizes our findings. We found significant challenges to the prevention approach due to the unpredictable and unfolding nature of medical care, rendering the ability to predict mishaps, and therefore to plan to prevent them, difficult. Yet our findings also suggest factors that challenge the effectiveness of resilient reliability, which entails the capacity to cope with lapses as they happen. Namely, actors often do not know that a lapse in reliability is occurring until it is too late, and even when they do realize that it is occurring, the nature of the lapse may be such that there is nothing they can do to mitigate it. Thus, real-time coping frequently is not a viable option. Furthermore, even when it is a viable option, features that shape actors' sensemaking during critical moments, namely identity and relational concerns, can prevent resilient coping in real-time.

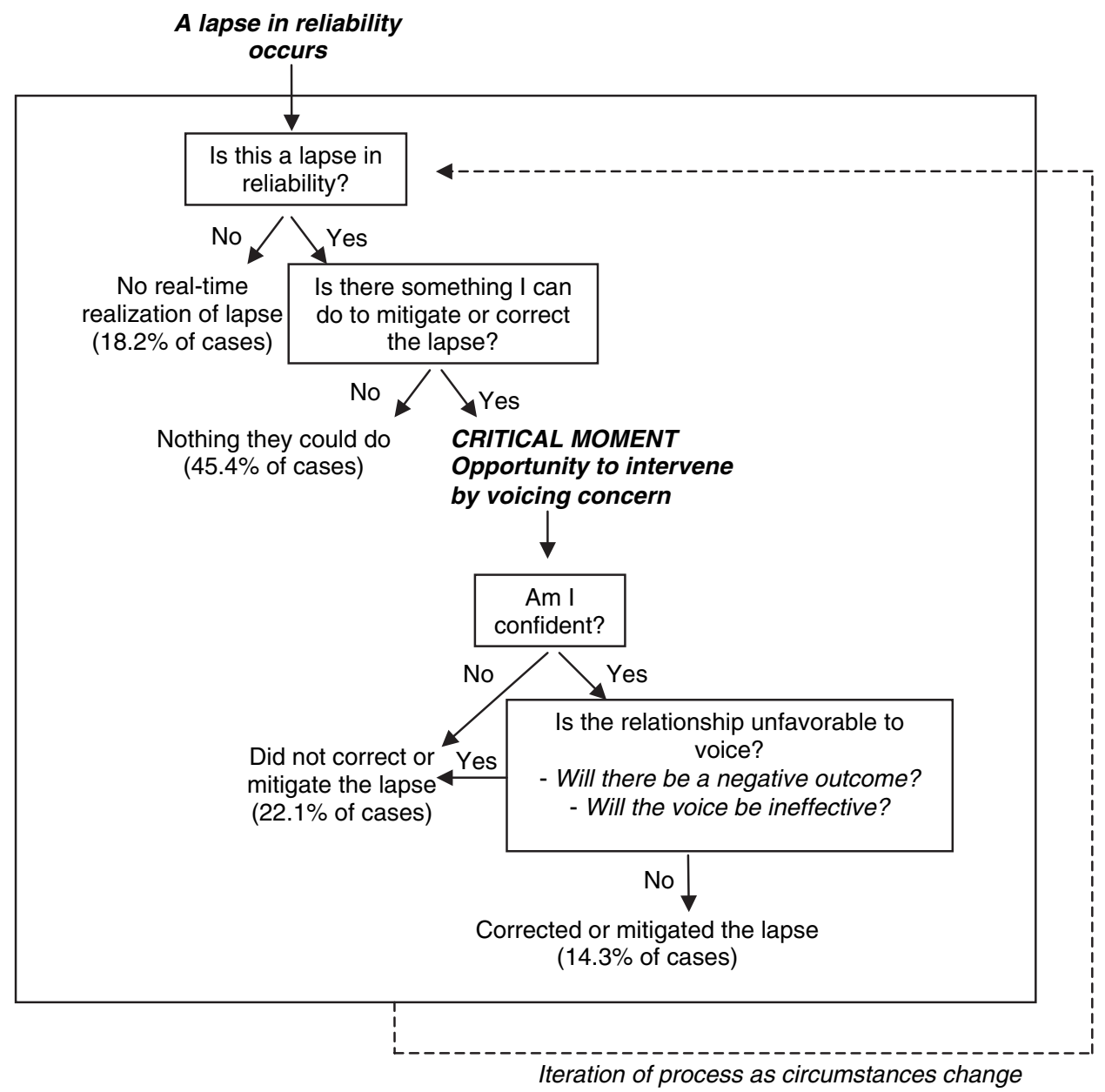

Figure 1. A sensemaking lens on lapses in reliability 
During critical moments, moments in which actors notice that a lapse in reliability has occurred and have an issue of concern to voice that may help mitigate or correct it, they engage in a process of sensemaking that has two components: first, it involves an assessment of confidence in the issue at hand, and second, it involves an assessment of the favorability of the relationship with the person to whom the actor would voice the concern. If an actor is confident and they have no indication that the relationship is unfavorable, then they are likely to voice their concern. If, however, they lack confidence or determine that the relationship is unfavorable, they may ultimately remain silent. This sensemaking process is iterative, whereby an initial choice to voice may eventually result in silence. Our findings suggest that this silence can contribute to adverse consequences for patients.

\section{Contribution to the voice and silence literatures}

Our findings that processes around individual silence play a role in lapses in reliability and their consequences contribute to the growing literature aimed at understanding when and why individuals choose to speak up (e.g., Dutton \& Ashford, 1993) or remain silent (e.g., Morrison \& Milliken, 2000; Journal of Management Studies Special Issue, September 2003) about issues of concern at work. Unlike previous studies in this stream of research, which asked respondents specifically about incidences in which they had voiced (Dutton, Ashford, Lawrence, \& Miner-Rubino, 2002) or remained silent (Milliken \& Morrison, 2003), we did not ask respondents specifically about voice or silence. Rather, we asked them to provide an account of what happened leading up to and after a medical mishap. This method enabled us to extend the current literature in several ways.

First, we contribute by showing that actors undergo a process of sensemaking about the issue itselfthat is, whether there is anything to voice or remain silent about - whereas current literature often treats the issue as clear-cut. For example, scholars studying how employees decide whether to voice ideas about strategic issues to upper management examine how the individual decides whether the organizational conditions are favorable to voice an issue he or she has identified to be important (Dutton \& Ashford, 1993; Milliken et al., 2003; Van Dyne et al., 2003). The decision to voice begins with the issue already clear. We take a few temporal steps back to identify the important role of sensemaking about whether there is an issue to voice and how confident the actor is about voicing it as an inherent part of the voice and silence process.

Second, in contrast to studies that suggest that a stable set of organizational conditions (e.g., Morrison \& Milliken, 2000) or stable attributions of the actor (e.g., Van Dyne et al., 2003) account for why actors voice or silence issues of concern, our findings reveal the influential role of particular relationships at a particular point in time. That is, actors assess and reassess the relational environment in real-time and remain silent if they sense that voicing a concern will either lead to a negative outcome for the self or others or will be ineffective. This suggests that adopting a relational orientation is useful for understanding the processes underlying voice and silence in organizations. Moreover, it shifts attention away from personality differences or social structures (e.g., climate) as mechanisms to explain patterns of behavior toward factors in the relationships between particular people at work, or what occurs in the 'space between' them (Bradbury \& Lichtenstein, 2000).

Third, our findings suggest that voice and silence are not single choice points, nor is one at the exclusion of the other, but rather that voice and silence are part of an iterative and dynamic process. The voice and silence literature has tended to imply that a communication is either voice or silence, and that once an issue is voiced, or, conversely, not voiced, the episode has ended. This characteristic results in part from the methods that have been used, which have focused on voice or silence around a single issue, focusing on the final outcome rather than the process. By adopting a sensemaking lens, we found 
that once voice or silence has been enacted, changing conditions ensure that the process continues, whereby initial voice may be followed by silence and vice versa.

Finally, although silence played a consequential role in lapses in reliability, our data were filled with examples in which residents continually voiced issues of concern as part of the day-to-day caring for patients. Overall, this observation suggests that silence is the exception rather than the rule, which contrasts with existing portrayals found in the voice and silence literature. For example, in their landmark paper, Morrison and Milliken (2000) focused attention on organizational silence as a prevalent and worrisome organizational phenomenon. Our findings portray a somewhat different landscape with respect to voice and silence in the healthcare setting.

\section{Contribution to the organizational reliability literature}

We contribute also to the literature on organizational reliability. Earlier we noted that our findings raise questions about the applicability of both the prevention and resilience approaches to reliability. The majority of incidents did not appear to lend themselves to prevention, mitigation, or correction, at least by the actors who experienced them, though we cannot assess from our data the extent to which these lapses could have been prevented upstream before the actor became involved. Moreover, our findings suggest that the ability to manage lapses in real-time often is limited because actors find themselves in situations where the consequences of the lapses have already occurred or where consequences are coincident with lapses. Theories of resilient reliability presume that individuals are able to notice and act upon anomalies as they unfold in real-time, especially if they are located in contexts that encourage mindful organizing practices (Weick et al., 1999). Our findings appear to support Ramanujam and Goodman's (2003: 24) observation that mindfulness is a useful concept, but that its usefulness may be limited in contexts characterized by distributed work (both temporally and geographically), low sequential interdependence (high reciprocal interdependence), or high instability.

If, as our findings show, both models of reliability have some features of potential usefulness to healthcare organizations as well as some limits, the question remains: How can reliability be achieved? Although it is not yet clear what a third approach to reliability would be, it will likely be a combination that incorporates the strengths of both approaches while addressing the limitations of each. Recent innovations in high-reliability organizing suggest that one means for combining the approaches may be instituting a set of roles, artifacts, decision support tools, or other practices that are embedded in the organizational context, and are thus not dependent on particular people for their effect (Bechky, 2006; Callero, 1994; Schulman, Roe, van Eeten, \& de Bruijne, 2004). Future researchers should explore how to combine the resilience and prevention approaches in ways that take advantage of their strengths while minimizing their limitations in this context.

We also contribute to the literature on reliability by better understanding factors that either enable or inhibit exercising agency during lapses of reliability. By agency, we mean intentional action undertaken by individuals to exercise influence or cause certain outcomes (Bandura, 2001). Many studies of error have emphasized the ubiquity of individual error (Reason, 1990) and the inevitability of organizational error (i.e., latent error), particularly in hazardous organizational settings (Perrow, 1984; Reason, 1997; Vaughan, 1996), and de-emphasized or neglected the role of agency in preventing error. Other theories suggest that agency is unbounded (Bigley \& Roberts, 2001; Weick \& Roberts, 1993; Weick et al., 1999) and do not fully specify the mechanisms through which it is either enabled or inhibited. Our findings provide insight into the identity issues and relational dynamics involved in promoting or inhibiting agency in the detection and management of lapses of reliability. 


\section{Contribution to healthcare}

Lastly, we contribute to the growing body of knowledge around medical error. Our findings suggest that a larger portion of errors than anticipated may not be able to be detected and corrected in real-time, highlighting how difficult error detection and correction is. We identify some of the factors that make individuals more likely to speak up about issues of concern regarding the patient, whatever those concerns might be. We move away from a specific typology of error and, instead, join with other scholars, such as Wears and Cook (2004), to call for research aimed at unpacking the mechanisms through which individuals are able to detect and correct errors earlier in their development.

Practically speaking, our findings have implications for healthcare organizations seeking to make systematic changes aimed at increasing the safety of patients (decreasing error). A heightened awareness of the difficulty of error detection and correction coupled with an appreciation of the fragility of critical moments for voicing concerns should prompt healthcare organizations to attend to developing relational competence for healthcare providers. Relational competence could be developed, for example, through enhancing providers' respectful engagement skills, namely ways to affirm others and listen in a way that manifests appreciation of another's worth (Dutton, 2003) or improve providers' communication skills, such as balancing advocacy and inquiry in their interaction (Losada \& Heaphy, 2004). These interventions are likely to reduce existing barriers to voicing concerns that are situated in the context of specific relationships.

\section{Limitations and Conclusion}

Our study's contributions should be considered in light of its limitations. First, residents may have selectively reported on what they had done right rather than wrong. Thus, for example, they may have over-reported on instances in which their opinions about patient care-whether voiced or silencedwere correct rather than incorrect. Thus our claim that voice can correct or mitigate a lapse in reliability presumes that the opinion to be voiced is valid.

Second, although we make claims about the sensemaking processes associated with lapses in reliability, we base these claims on interview data rather than on observing the processes directly. This is clearly a limitation of our study. However, several reasons suggest that our data offer an interesting starting point for understanding sensemaking processes. First, we agree with scholars (e.g., Orlikowski, 2002) who argue that people are more knowledgeable and reflexive about (and can give a reasonable account of) what they do than many researchers give them credit for. Second, we join other sensemaking researchers who use interview data as windows into people's 'accounts' about their work (Maitlis, 2005). Accounts and other related concepts, such as stories and narratives, are ways in which people organize and construct ordered relationships among events, people, actions, and things to obtain a coherent view of themselves, others, and their social world (Orbuch, 1997). Accounts are critical resources that guide future behavior because they give people a sense of control and understanding of their environment in ways that enable them to act (Maitlis, 2005). To the extent that the accounts respondents generated in the interviews reflect the accounts they use as a basis for action in their day-today work, then these accounts can be informative about the process of coping with lapses in reliability in real-time.

In closing, accounts from the front line reveal a complicated picture of lapses in reliability in dynamic organizational contexts that challenges current theories on reliability. Not all lapses in reliability are the same and only in a subset can actors usefully intervene in real-time. Yet even when 
they can, they often do not. Our findings suggest that future work on reliability in dynamic organizational settings will benefit from methodologies that explore the perspective of organizational actors as they deal with day-to-day fluctuations in their work. Moreover, our research highlights the importance of exploring the role of the sensemaking process and factors that shape it on how and why lapses in reliability occur and can be managed.

\section{Acknowledgement}

We thank Ranga Ramamujam, Adam Grant, Tim Vogus, and two anonymous reviewers for constructive comments on previous drafts.

\section{Author biographies}

Ruth Blatt is a PhD student in Management \& Organizations at the University of Michigan. Her research focuses on the personal and relational consequences of transience and dynamism at work. Topics of interest include meaning-making, positive relationships, helping, and coordination.

Marlys Christianson is a PhD student in Management \& Organizations at the University of Michigan. Her research focuses on how organizational structures and practices build capabilities within organizations. Topics of interest include mindful organizing, coordination of work, well-being, and thriving.

Kathleen Sutcliffe is a professor of Management and Organizations at the University of Michigan. Her research is focused on managerial and organizational cognition, processes of learning, reliability, and resilience, and how an organization's design contributes to its members' abilities to sense, cope with, and respond to changing demands.

Marilynn Rosenthal is professor emerita of sociology and currently adjunct professor in internal medicine at the University of Michigan Medical School. Her research is focused on medical error and public policy in healthcare.

\section{References}

Bandura, A. (2001). Social cognitive theory: An agentic perspective. Annual Review of Psychology, 52, 1-26.

Bechky, B. A. (2006). Coordination in context: A work-based approach to coordination in organizations. Working paper, Graduate School of Management, UC Davis.

Bigley, G. A., \& Roberts, K. H. (2001). The incident command system: High-reliability organizing for complex and volatile task environments. Academy of Management Journal, 44, 1281-1299.

Bradbury, H., \& Lichtenstein, B. M. B. (2000). Relationality in organizational research: Exploring the space between. Organization Science, 11, 551-564.

Brown, A. (2000). Making sense of inquiry sensemaking. Journal of Management Studies, 37, 45-75.

Callero, P. L. (1994). From role-playing to role-using: Understanding role as resource. Social Psychology Quarterly, 57, 228-243. 
Carthey, J., de Leval, M. R., \& Reason, J. T. (2001). Institutional resilience in healthcare systems. Quality in Health Care, 10, 29-32.

Dutton, J. E. (2003). Energize your workplace: How to build and sustain high-quality connections at work. San Francisco: Jossey-Bass.

Dutton, J. E., \& Ashford, S. J. (1993). Selling issues to top management. Academy of Management Review, 18, 397-428.

Dutton, J. E., Ashford, S. J., Lawrence, K. A., \& Miner-Rubino, K. (2002). Red light, green light: Making sense of the organizational context for issue selling. Organization Science, 13, 355-369.

Edmondson, A. (1999). Psychological safety and learning behavior in work teams. Administrative Science Quarterly, 44, 350-383.

Edmondson, A. C. (2003). Speaking up in the operating room: How team leaders promote learning in interdisciplinary action teams. Journal of Management Studies, 40, 1419-1452.

Ewich, P., \& Silbey, S. B. (1995). Subversive stories and hegemonic tales: Toward a sociology of narrative. Law \& Society Review, 29, 197-226.

Glaser, B. G., \& Strauss, A. L. (1967). The discovery of grounded theory: Strategies for qualitative research. New York: Aldine de Gruyter.

Hayward, R. A., \& Hofer, T. P. (2001). Estimating hospital deaths due to medical errors: Preventability is in the eye of the reviewer. Journal of the American Medical Association, 286, 415-420.

Hoff, T. J., Jameson, L., Hannan, E., Flink, E., \& Osten, W. (2004). A review of the literature examining linkages between organizational factors, medical errors, and patient safety. Medical Care Research and Review, 61, 3-37.

Kohn, L. T., Corrigan, J. M., \& Donaldson, M. S. (2000). To err is human: Building a safer healthcare system. Washington, DC: National Academy Press.

Lee, T. W., Mitchell, T. R., \& Sablynski, C. J. (1999). Qualitative research in organizational and vocational psychology, 1979-1999. Journal of Vocational Behavior, 55, 161-187.

Lin, A. C. (1998). Bridging positivist and interpretivist approaches to qualitative methods. Policy Studies Journal, $26,162-180$.

Locke, K. (2001). Grounded theory in management research. Thousand Oaks, CA: Sage.

Losada, M., \& Heaphy, E. (2004). The role of positivity and connectivity in the performance of business teams: A nonlinear dynamics model. American Behavioral Scientist, 47, 740-765.

Maitlis, S. (2005). The social processes of organizational sensemaking. Academy of Management Journal, 48, 21-49.

Miles, M. B., \& Huberman, A. M. (1994). Qualitative data analysis: An expanded sourcebook. Thousand Oaks, CA: Sage.

Milliken, F. J., \& Morrison, E. W. (2003). Shades of silence: Emerging themes and future directions for research on silence in organizations. Journal of Management Studies, 40, 1563-1568.

Milliken, F. J., Morrison, E. W., \& Hewlin, P. F. (2003). An exploratory study of employee silence: Issues that employees don't communicate upward and why. Journal of Management Studies, 40, 1453-1476.

Morrison, E. W., \& Milliken, F. J. (2000). Organizational silence: A barrier to change and development in a pluralistic world. Academy of Management Review, 25, 706-725.

Orbuch, T. L. (1997). People's accounts count: The sociology of accounts. Annual Review of Sociology, 23, 455478.

Orlikowski, W. J. (2002). Knowing in practice: Enacting a collective capability in distributed organizing. Organization Science, 13, 249-273.

Paget, M. A. (1988). The unity of mistakes. Philadelphia, PA: Temple University Press.

Paget, M. A. (1990). Life mirrors work mirrors text mirrors life. Social Problems, 37, 137-148.

Patriotta, G. (2003). Sensemaking on the shop floor: Narratives of knowledge in organizations. Journal of Management Studies, 40, 349-376.

Patterson, E. S., Cook, R. I., Woods, D. D., \& Render, M. L. (2006). Gaps and resilience. In M. S. Bogner (Ed.), Human error in medicine (2nd ed.). Hillsdale, NJ: Lawrence Erlbaum Associates.

Perrow, C. (1984). Normal accidents: Living with high-risk technologies. New York: Basic Books.

Ramanujam, R., \& Goodman, P. S. (2003). Latent errors and adverse organizational consequences: A conceptualization. Journal Of Organizational Behavior, 24, 815-836.

Reason, J. (1990). Human error. New York: Cambridge University Press.

Reason, J. (1997). Managing the risks of organizational accidents. Brookfield, VT: Ashgate Publishing.

Rosenthal, M. M., \& Sutcliffe, K. M. (2002). Medical error: What do we know? What do we do? San Francisco, CA: Jossey-Bass.

Schulman, P. R. (2004). General attributes of safe organizations. Quality and Safety in Health Care, 13, 39-44. 
Schulman, P. R., Roe, E., van Eeten, M., \& de Bruijne, M. (2004). High reliability and the management of critical infrastructures. Journal of Contingencies and Crisis Management, 12, 14-28.

Snook, S. A. (2000). Friendly fire: The accidental shootdown of U.S. black hawks over Northern Iraq. Princeton, NJ: Princeton University Press.

Solet, D. J., Norvell, J., Rutan, G. H., \& Frankel, R. M. (2005). Lost in translation: Challenges and opportunities in physician-to-physician communication during patient handoffs. Academic Medicine, 80, 1094-1099.

Sutcliffe, K. M., Lewton, E., \& Rosenthal, M. M. (2004). Communication failures: An insidious contributor to medical mishaps. Academic Medicine, 79, 186-194.

Sutcliffe, K. M., \& Vogus, T. J. (2003). Organizing for resilience. In K. S. Cameron, J. E. Dutton, \& R. E. Quinn (Eds.), Positive organizational scholarship: Foundations of a new discipline (pp. 94-110). San Francisco, CA: Berrett-Koehler.

Taylor, J. R., \& Van Every, E. J. (2000). The emergent organization: Communication as its site and surface. Mahwah, NJ: Erlbaum.

Thomas, E. J., Lipsitz, S., Studdert, D. M., \& Brennan, T. A. (2002). The reliability of medical record review for estimating adverse event rates. Annals of Internal Medicine, 136, 812-816.

Van Dyne, L., Ang, S., \& Botero, I. C. (2003). Conceptualizing employee silence and employee voice as multidimensional constructs. Journal of Management Studies, 40, 1359-1392.

Vaughan, D. (1996). The challenger launch decision. Chicago: University of Chicago Press.

Vidyarthi, A. (2004). Fumbled Handoff, Hospital Medicine. Agency for Healthcare Research and Quality. Retrieved February 12, 2006, from Agency for Healthcare Research and Quality Website: www.webmm. ahrq.gov/case.aspx?caseID $=55$.

Volpp, K. G. M., \& Grande, D. (2003). Residents' suggestions for reducing errors in teaching hospitals. New England Journal of Medicine, 348, 851-855.

Wears, R. L., \& Cook, R. I. (2004). The illusion of explanation. Academic Emergency Medicine, 11, $1064-1065$.

Weick, K. E. (1990). The vulnerable system: An analysis of the Tenerife air disaster. Journal of Management, 16, 571-593.

Weick, K. E. (1995). Sensemaking in organizations. Thousand Oaks, CA: Sage.

Weick, K. E., \& Roberts, K. H. (1993). Collective mind in organizations: Heedful interrelating on flight decks. Administrative Science Quarterly, 38, 357-381.

Weick, K. E., Sutcliffe, K. M., \& Obstfeld, D. (1999). Organizing for high reliability: Processes of collective mindfulness. In B. M. Staw, \& R. Sutton (Eds.), Research in organizational behavior (Vol. 21, pp. 81-123). Greenwich, CT: JAI Press.

Weick, K. E., Sutcliffe, K. M., \& Obstfeld, D. (2005). Organizing and the process of sensemaking. Organization Science, 16, 409-421.

Wildavsky, A. (1991). Searching for safety. New Brunswick: Transaction Books.

Yin, R. K. (1994). Case study research: Design and methods. Thousand Oaks, CA: Sage. 